\title{
Recent Animal Disease Outbreaks and their Impact on Human Populations ${ }^{1}$
}

\author{
Jeff B. Bender, William Hueston and Micheal Osterholm \\ University of Minnesota \\ St. Paul, Minnesota \\ bende@umn.edu
}

Animals occupy a special place in human societies. They are utilized for food (e.g., milk and meat), transportation, raw materials (e.g., wool and hides), energy (e.g., manure), recreation, and money (e.g., bartering). Furthermore, animals such as dogs, cats, and horses in some societies often are viewed as "companions." Their value in long-term care facilities and for the emotional well-being of AIDS patients has been documented (Siegel et al., 1999). In addition to these valuable contributions, there is growing concern about diseases that humans can acquire from animals (e.g., zoonoses). Zoonoses are overrepresented among human diseases that are defined as emerging (Table 1). Taylor et al. (2001) documented that $61 \%$ of all human pathogens are zoonotic. And of the 175 newly emerging pathogens in humans, $75 \%$ are listed as zoonotic (Cleaveland et al., 2001). From 1996 to 2006, eleven of the twelve global emerging diseases originated from animals (Gerberding, 2004).

However, it is also important to remember that some diseases affect animals only, often with economic, environmental and/or societal implications. Recent examples include chronic wasting disease in elk and deer, foot-and-mouth disease, toxoplasmosis in sea otters, and salmonella in song birds. In 1994, canine distemper jumped the "species-barrier" and infected African lions of the Serengeti (Roelke-Parker et al., 1996), killing over a third of the population within 6 months.

\footnotetext{
${ }^{1}$ Adapted from Bender JB et al. (2006) Recent animal disease outbreaks and their impact on human populations. Journal of Agromedicine 11(1) 5-15.
} 


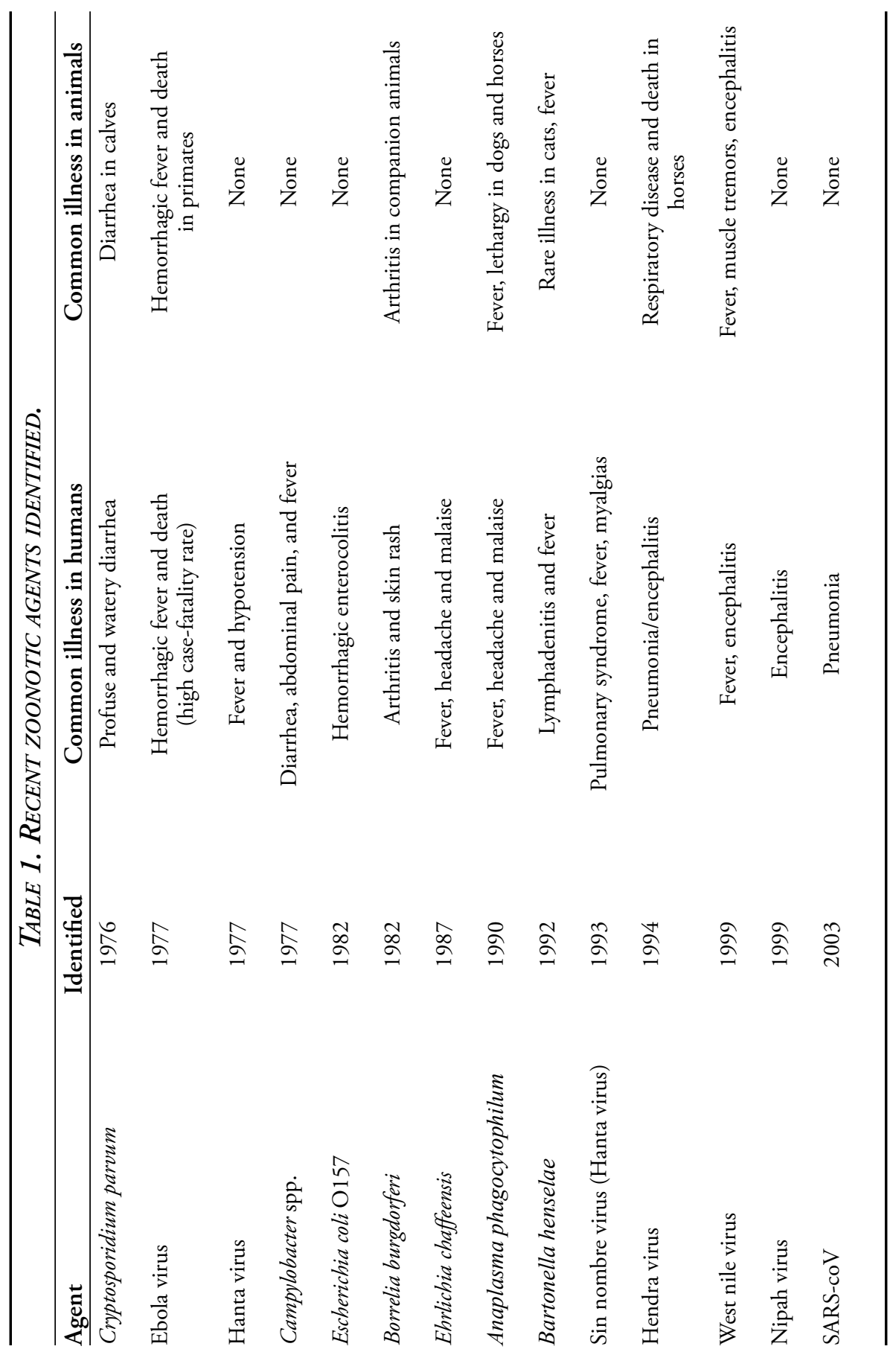


New diseases emerge for a number of reasons: world trade, animal translocation, ecological disruption, climate change, pathogen adaptation, and agricultural husbandry changes (Smolinski et al., 2003). These factors represent the dynamic relationships among the pathogenic agent, host, and environment (Figure 1). This epidemiologic triangle includes the intrinsic characteristics of an individual's susceptibility to disease, including immune status, general health, genetic makeup, lifestyle, age, sex, and socioeconomic status, and extrinsic factors, which include the host's biological, social, and physical environment. Coincidentally, the triangle describing this relationship is the same as delta, the symbol for change; change is the one constant in the on-going tension between humans and microbes.

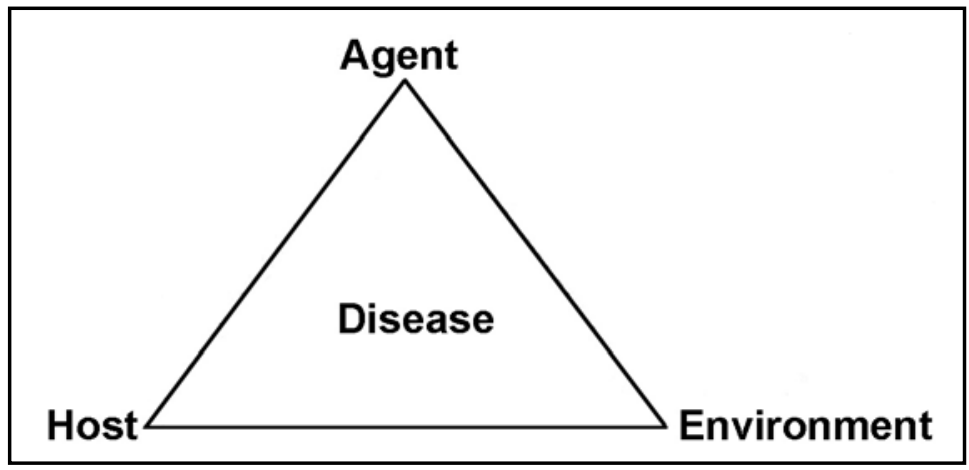

Figure 1. The epidemiologic triangle.

This article will discuss some recent outbreaks of disease, lessons learned, and challenges for the future. We will describe:

- the strong connection between animals and humans,

- the challenge of effective risk communication where there is limited knowledge of the risks,

- the dwindling and fragile animal-health and public-health systems,

- the lack of oversight and regulations to prevent disease transmission,

- changes in agricultural practices that result in new or re-emerging diseases, and

- the relationship between culture and disease.

We will discuss the specific examples of foot-and-mouth disease (FMD), chronic wasting disease (CWD), monkeypox, severe acute respiratory syndrome (SARS), and avian influenza.

\section{The Strong Connection Between Animals and Humans}

\section{Foot-and-Mouth Disease}

Some diseases may not have a direct impact on human health but, nonetheless, exert significant societal pressure by disrupting local economies as well as world trade. This is exemplified by the 2001 outbreak of FMD in the United Kingdom, which spread to other countries in Europe (Figure 2). 


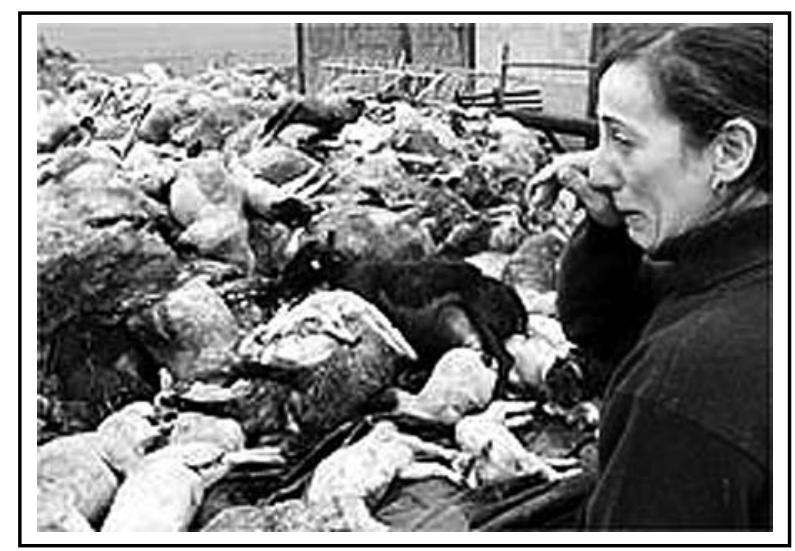

Figure 2. The impact of culling sheep during the outbreak of foot and mouth disease in France, 2001.

Foot-and-mouth disease is primarily a disease of cloven-footed domestic and wild animals. It is endemic in Asia, Africa, and parts of South America. However, some areas of the world are free of FMD, including North and Central America, Australia, New Zealand, Japan and most European countries. The causal agent is considered one of the most highly contagious viruses, and its contagiousness has huge implications on trade of livestock and livestock products. The disease may spread by direct or indirect contact with infected animals, aerosol from infected animals or milk trucks, and fomites, as well as through artificial insemination. People who come into contact with infected animals can serve as mechanical vectors, as sufficient FMD virus survives in their upper airways for 24 hours to potentially serve as an ongoing source of infection to livestock (Sellers et al., 1971).

During the FMD outbreak in the United Kingdom in 2001, an estimated 2,000 confirmed cases and an additional 6 million animals were slaughtered to achieve containment (DEFRA, 2005a). The cost of controlling the outbreak and losses due to decreased tourism were estimated at $£ 6.2$ billion (DEFRA, 2005a). The postulated source was illegally imported food that eventually ended up as scraps in garbage fed to pigs (DEFRA, 2005b). The psychological and economic impact on the British population-farmers and nonfarmers alike-was huge. Increases in suicides among farmers were reported and substantial economic losses were incurred from a trade embargo, travel restrictions, and reduced tourist income (DEFRA, 2005a). This does not take into account the loss of genetic stock and the cost of controlling the outbreak. A psychological assessment of the impact of FMD noted that farmers in the impacted area had significantly higher psychological morbidity scores compared to farmers in non-impacted areas (Peck et al., 2002).

\section{Cryptosporidiosis}

Although FMD rarely is detected in humans, human health did not go entirely unaffected by the outbreak. The presence of FMD, an exotic animal disease, correlated with a decreased incidence of an endemic zoonotic disease, cryptosporidiosis, caused 
by Cryptosporidium parvum. Cryptosporidiosis is the most common parasitic infection among people in the United Kingdom, where an estimated two-thirds of cases are due to $C$. parvum. Two separate reports described a significant drop in Cryptosporidium cases during the FMD outbreak. Hunter et al. (2003) reported a 69\% decline in cases in the northwest of England (Figure 3). Strachan et al. (2003) reported a 34\% decline in Scotland, with a noticeable difference between FMD-infected areas and FMD-free areas. Reasons for these reductions were restrictions of farm-animal movement, possibly the presence of fewer young animals (the major source of exposure), and fewer animal-to-human interactions that allow transmission.

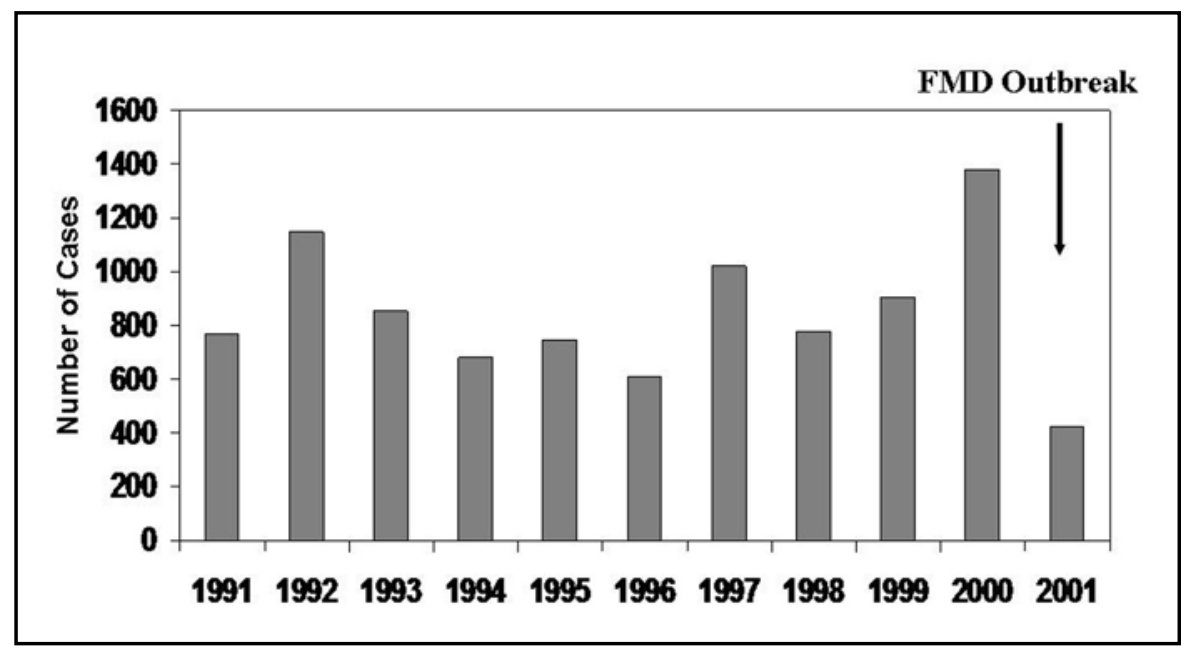

Figure 3. Reported cases of cryptosporidiosis in northwest England, 1991-2001 (Hunter et al., 2003).

This outbreak of FMD highlights the strong and varied interrelationships between animals and humans. Although it is a disease primarily of animals with limited direct transmission to humans, it can have a significant public-health impact in terms of psychological effects, and its presence can send shockwaves through local economies. In addition, FMD is one of the primary agents of concern for agroterrorism, not only because of the economic and trade ramifications it can inflict on the livestock industry, but also because of the severe societal impact it may have. We must never underestimate the societal impact of diseases even when they directly impact the health only of animals.

\section{A Challenge in Effective Risk Communication}

A second animal disease capturing the headlines is CWD, a disease of the nervous system found in Cervidae: white-tailed deer, mule deer, black-tailed deer, and elk. CWD belongs to the family of diseases known as transmissible spongiform encephalopathies or prion diseases, and is a slowly progressive, invariably fatal neurologic disease in cervids. First 
recognized as a new disease among captive mule deer in a Colorado wildlife unit, it was later found to be endemic in both mule deer and elk in Colorado and Wyoming (Williams and Miller, 2003). The origin of the disease is unknown, but some have speculated that CWD 1 (Williams and Miller, 2003):

- is an adapted strain of the scrapie agent found in sheep,

- arose as a spontaneous evolutionary event, or

- originated from a yet unidentified prion reservoir.

CWD has been found in various areas throughout North America, both in captive and in free-ranging cervids (Figure 4). The perceived spread from the initial endemic areas is likely attributable to the movement of deer and elk in commerce, local expansions of farmed herds, and increased surveillance efforts (Williams and Miller, 2003).

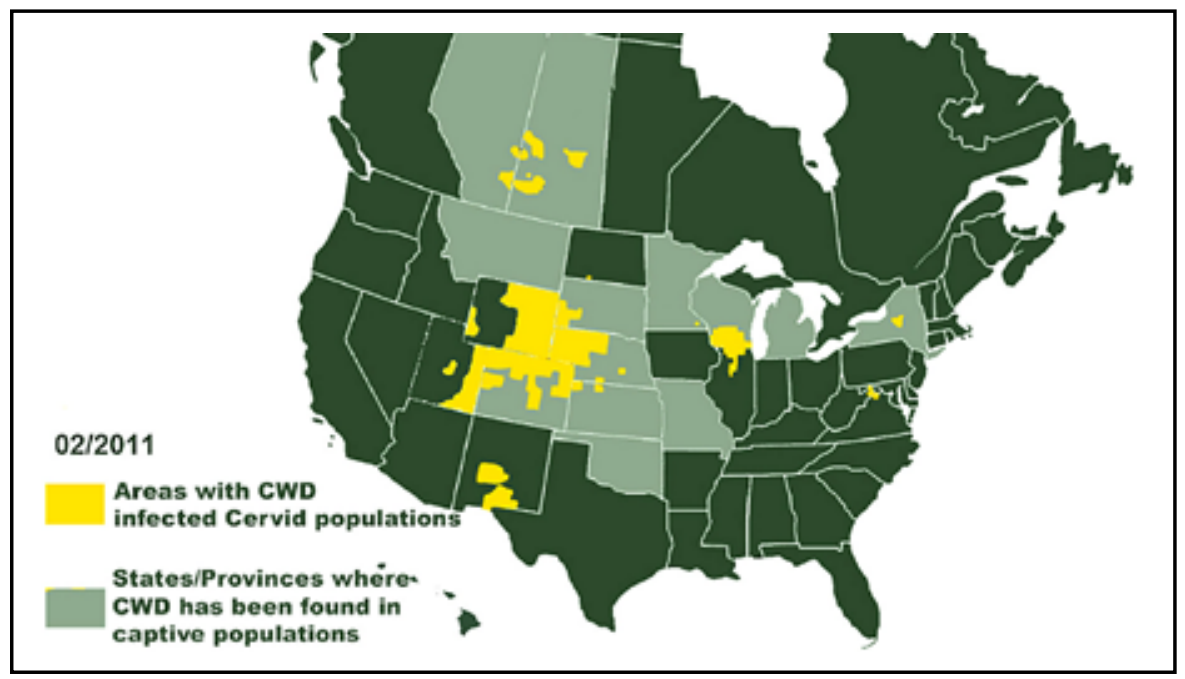

Figure 4. Chronic wasting disease in captive and free-ranging cervids (courtesy of the Chronic Wasting Disease Alliance, http://www.cwd-info.org/index.php/fuseaction/about.map).

Since cervids were found to have CWD, hunters, farmers and venison consumers have become concerned about the risk of zoonotic transmission, largely because of the connection between bovine spongiform encephalopathy (BSE) and variant CruetzfeldtJakob disease (vCJD). Creutzfeldt-Jakob disease occurs around the world at a rate of 1-2 per million humans. The majority of cases has occurred among British citizens and persons who have resided in the United Kingdom. All vCJD cases to date have lived in countries with BSE.

If CWD is a zoonotic disease, what would it look like in humans? Would people living in endemic areas be at greater risk? To date, investigators have not seen higher numbers of human spongiform encephalopathies in CWD-endemic areas. However, prion diseases 
are rare, have long incubation periods, and can be difficult to detect. Because of recent concerns about prion diseases, epidemiologists are investigating neurologic diseases focusing on young people with unusual clinical presentations or neuropathology. Several documented clusters of cases have been investigated, often in response to concern from family members believing that deer-meat consumption was linked to illness (Belay et al., 2004). These cluster investigations are a challenging exercise in risk communication about human and animal health. One investigation involved three elderly men, all of whom had a history of eating venison, who died of degenerative neurologic illnesses (CDC, 2003a). However, further diagnostic work-up revealed that only one actually had evidence of a prion disease. Currently, it is the consensus of the World Health Organization and the Centers for Disease Control and Prevention that there is no scientific evidence that CWD causes human illness (Belay et al., 2004; WHO, 2005).

As with FMD, CWD has a psychological impact on humans although it does not directly harm human health. No definite link has been found between CWD and human brain disease, yet the detection of CWD in free-ranging deer in Wisconsin and Illinois in 2002 had a substantial impact on the human psyche. Nine months after CWD was discovered in Wisconsin, there was an $11 \%$ drop in deer-license sales (Heberlein, 2004). Also, similar to FMD, the discovery of CWD hurt local economies. Businesses that served Wisconsin hunters saw sharp declines in sales, as did feed dealers and local butcher shops. The decrease in license sales resulted in reduced revenues for the State of Wisconsin, and state expenditures increased $\$ 14.7$ million to control CWD; overall, the estimated economic impact in 2002 was between $\$ 53$ and $\$ 79$ million (Bishop, 2004). This situation illustrates the emotional and economic impacts of infectious diseases and the challenge of effectively communicating evolving risk with reference to emerging animal diseases.

\section{Dwindling and Fragile Animal- and Public-Health INFRASTRUCTURE}

National economies are vulnerable to outbreaks of animal disease, both intentionally malicious and accidental. Recent terrorist attacks have exposed the vulnerability of our transportation, food, and medical infrastructure. Several episodes have been documented in which food was intentionally contaminated for terrorist purposes (Manning et al., 2005). However, in recent years, the most dramatic impact on national economies has not come from terrorism, but from the accidental introduction of foreign animal diseases. The threat is very real when we consider the volume of travelers and traffic that enter the United States each year, both legally and illegally. There is no feasible way for each vehicle and piece of luggage to be thoroughly checked for microscopic travelers. In addition, millions of animals and animal products are imported. They can serve as silent disease carriers or can harbor insects and ticks that serve as disease vectors. Clearly, we need to give greater attention to training of, and cooperation among, veterinarians, livestock producers, extension personnel, and healthcare professionals. Specifically, since some of these diseases can be zoonotic, veterinarians and people who work to protect human health need to combine forces to quickly diagnose and control their spread, especially in rural communities. 
The West Nile virus is another dramatic example of the animal- and public-health challenges of understanding an emerging disease with only limited personnel dedicated to understanding insect vectors and viral spread through wild-bird hosts. Originally a disease of Africa and Europe, it was first observed in New York in 1999 (Lanciotti et al., 1999). Initially misdiagnosed as St. Louis encephalitis, this disease, new to the Western hemisphere, was astutely diagnosed with the combined efforts of a veterinary pathologist, a physician, and epidemiologists. The virus now has been documented in all states of the continental United States. Migratory birds and competent mosquito vectors were instrumental in the rapid westward spread. The ensuing epizootic has had a dramatic effect on horse, bird, and human populations. In 2002, over 15,000 horses were reported ill, and $30 \%$ died as a result of the infection (CDC, 2002a). The impact on raptors and corvids (blue jays and American crows) has also been well documented (Wunschmann et al., 2004). However, the broader impact within ecosystems, especially on wildlife, is unknown. From 1999 through 2004, over 16,700 human cases and 666 deaths were reported in the United States (Hayes and Gubler, 2005). This disease highlights some of the new challenges for human clinicians of unusual disease presentations (e.g., acute flaccid paralysis syndrome) and new routes of transmission (e.g., blood transfusion and organ transplantation). The appearance of West Nile virus required the training and funding of public-health officials in mosquito trapping, vector control, and close collaboration with academic institutions for disease surveillance and public education.

\section{Lack of Oversight and Regulations}

Monkeypox was first documented in 1958 in a colony of primates (hence the term). The first human cases were identified in 1970 in Zaire by local health officials on the lookout for the re-emergence of the smallpox virus. This rare disease was documented among people who lived where hunting was an integral aspect of their lifestyle. The natural disease hosts are likely several species of squirrel.

In 2003, an outbreak in the United States associated with legally imported African "pocket pets" led to seventy-two suspected human cases in six states (CDC, 2003b). Eighteen persons were hospitalized, some because of the potential for human-to-human spread. Interestingly, a number of the cases were veterinarians and veterinary technicians exposed while treating ill pets, highlighting potential occupational risk. The majority of patients had direct or close contact with prairie dogs that were infected by close contact with imported animals from Ghana, shipped to a distributor in Texas. The shipment included six genera of African rodents, including rope squirrels (Funiscuirus sp.), tree squirrels (Heliosciurus sp.), Gambian giant rats (Cricetomys sp.), brushtail porcupines (Atherurus sp.), dormice (Graphiurus sp.), and striped mice (Hybomys sp.). There was a real concern of spillover of the virus from these imported animals to susceptible wildlife populations in the United States.

Even though this outbreak was not directly related to agriculture, it exemplifies the problem of both legal and illegal animal movements. The US Fish and Wildlife Service estimates that the global trade in endangered wildlife is $\$ 4.2$ billion annually, second only to illegal drugs. Other examples of emerging diseases linked to live-animal trade, include 
the spread of rabies from trapping raccoons in Florida for game farms in West Virginia (CDC, 1981), the collection of prairie dogs for pet markets that were subsequently diagnosed with tularemia (CDC, 2002b), and the shipping of elk infected with CWD to Korea (Sohn et al., 2002). All of these examples clearly demonstrate potential consequences when humans move animals from one area to another and the need for regulations and federal policies that control the transfer/exchange of exotic animals. Currently, there are regulations for rodents from Africa and poultry from Southeast Asia, but numerous animals still pass through US ports unregulated (DHHS, 2003). Currently, no regulations control the interstate movement of exotic animals or wildlife within the United States.

\section{Changes in Agricultural Practices and Food Processing}

The emergence of BSE demonstrated the role of animal-feed commodities such as meat and bone meal (MBM) in the spread of disease. Meat and bone meal is an important recycled byproduct used as an inexpensive protein source. Since the 1950s, this protein source has increasingly been added to the diets of high-producing or rapidly growing animals, for example, beef and dairy cattle. While the BSE outbreak has largely been confined to Great Britain, the movement of affected animals and/or contaminated MBM spread the disease throughout Europe and beyond including sporadic cases in Japan and North America. As a result, "firewalls" were devised to decrease the amplification and spread of the disease when a clear understanding of the risks was identified.

In addition to changes in feed ingredients such as those that led to the spread of BSE, other agricultural and food-production factors that might appear to be innocuous can also provide a mechanism for disease transmission. For example some have speculated that the move from pasture feeding in the mid- $20^{\text {th }}$ century to intensive grain feeding has altered the gastrointestinal tracts of cattle in a way that favors the growth of Escherichia coli O157:H7 (Russell et al., 2000) A second example is Listeria monocytogenes, a bacterium recognized as an animal pathogen more than 100 years ago, but seen as a significant cause of human illness only since the 1980s. The emergence of L. monocytogenes as a foodborne pathogen is due to pathogen survival at refrigeration temperatures, the increasing number of immunocompromised individuals in the population, the centralization and consolidation of food production, and changes in consumer food habits (e.g. consumption of ready-to-eat foods) (Swaminathan, 2001). This disease reflects the impact of changing food-processing techniques, with which post-contamination of cooked foods can be a source of infection. These factors demonstrate the complex and evolving nature of pathogens and the need for animal- and public-health surveillance systems to quickly identify and characterize new and emerging pathogens.

\section{Cultural Practices and Disease Emergence}

In many communities, there exist cultural or societal practices that can inadvertently encourage disease transmission by artificially causing animals to congregate. Recently, Mycobaterium bovis was identified among deer in northern Michigan, and its presence was attributed to the congregation of the deer due to "baiting" or feeding by deerhunters (Miller $e t$ al., 2003). As a result, Michigan passed legislation prohibiting the feeding of 
deer in an attempt to limit the transmission of $M$. bovis. A similar phenomenon is occurring with birds: when songbirds congregate at feeders, their increased proximity can lead to the spread of salmonellosis and their subsequent illness and death.

Examples of global problems of disease transmission abound. In November 2002, the detection of an atypical pneumonia quickly challenged the world public-health system. SARS caused illness in over 8,000 persons around the world with 774 documented deaths. The identification of this rapidly spreading disease had a dramatic impact on healthcare workers and patients' willingness to utilize medical services (Emanuel, 2003; Chang et al., 2004; Maunder, 2004). Half of the first sixty cases identified were healthcare workers, but, despite the risk, they continued to care for patients. The impact was felt globally with cancelled air flights and record low hotel occupancy rates; for example, in Hong Kong hotels, they dropped to $17 \%$ compared to $83 \%$ a year earlier (Emanuel, 2003). The economic cost to Toronto, Canada, was estimated at nearly $\$ 1$ billion in 2003 (Blendon et al., 2004).

SARS is a corona virus that likely emerged from a wild-animal source (Lau et al. 2005). This is supported by the detection of initial cases among restaurant workers handling exotic animals in Guangdong Province (Zhong et al., 2003). SARS-CoV has also been isolated from masked palm civets and other wild animals in a live-animal market (Guan et al., 2003; Lau et al., 2005). Seroepidemiology of animal traders and handlers further supports this; $13 \%$ of animal traders had IgG antibody to SARS-CoV, as compared to 1 to $3 \%$ from community control groups (CDC, 2003c).

Researchers speculate that SARS-CoV likely originated from animals with which humans have infrequent contact, such as exotic species. The zoonotic link has been attributed to the phylogenetic relationship between corona viruses and those isolated from wild animals such as the palm civet and the raccoon dog. Contact likely occurred among southern Chinese who periodically consume wild-game meat for medicinal purposes. Zhong et al. (2003) have suggested that viruses that are transmitted between species tend to undergo more rapid genetic change as they adapt to new hosts. It is likely that novel viruses such as Ebola, HIV, and SARS-CoV will continue to appear with increased human interaction with wild animals. The lucrative wild-animal markets in Southeast Asia, a smorgasbord of wild and domestic animals, are often unregulated (Karesh et al., 2005).

Avian influenza is another example that illustrates the relationship of cultural and social practices and the appearance of animal disease. Southeast Asia is considered the epicenter of recent influenza outbreaks. This is linked to agricultural practices in a highly populated area. Rice fields often have standing water that attracts waterfowl. These waterfowl are natural reservoirs, potentially spreading the disease to other domestic animals (e.g. chickens, ducks, and pigs) raised outdoors. In 2005 it was estimated that there were 1.3 billion humans, 508 million pigs and 13 billion chickens in China (Osterholm, 2005). The identification of novel avian influenza strains over the past 15 years documents the continual re-assortment of influenza viruses among birds, pigs and humans. Fortunately, sustained human-to-human transmission has not been documented (Ungchusak et al., 2005). But with aquatic wild birds as the natural reservoir, it will be nearly impossible to eradicate this disease. The H5N1 strain responsible for the 1997 Hong Kong outbreak 
of influenza in domestic poultry resulted in the culling of 1.5 million birds and the identification of eighteen human cases with six deaths (Bridges et al., 2002). Similarly in the Netherlands, 28 million birds were culled with eighty-nine reported human cases and one death (Fouchier et al., 2004). The 2003-2005 H5N1 outbreaks in Asia affected eleven countries, with 109 reported human cases and fifty-five deaths (CIDRAP, 2005). Like SARS, the economic impact in Southeast Asia was substantial. The South Korean Ministry of Health and Welfare estimated that the cost of avian influenza to Asian countries at about $\$ 130$ billion. Unlike SARS, influenza is a potentially greater problem with a common wildlife reservoir (e.g. aquatic birds). This is complicated by minimal publichealth and medical infrastructure and large numbers of other potential reservoirs, such as pigs and domestic poultry commingling with humans in village settings. Avian influenza demonstrates the immediate need for international cooperation and interdisciplinary interventions for disease detection, control, and prevention. It also illustrates the need to engage local farmers in the development of sustainable strategies to identify suspect cases and prevent the commingling of domestic and wild-bird populations.

\section{SUMmary}

We face some critical needs as we combat emerging diseases. We must understand the global consequences of moving animals and animal products around the world and assess the impact of an increasing human population on the environment. This combination sets the stage for potential mixing of microorganisms around the globe in contact with susceptible populations. The influenza epidemic of 1918-1919 killed 50 to 100 million people worldwide, but since the 1960s, many of us have had the luxury of forgetting about the enormous death toll brought by outbreaks of infectious diseases (Osterholm, 2005). Even today, however, we cannot disregard the possible catastrophic effects of currently emerging diseases.

To control emerging diseases requires early detection and intervention. The phenomenal speed in the diagnosis and identification of the SARS-CoV demonstrates how technologies have improved our response and mitigation efforts. These rapid diagnostic tests need to be incorporated in the field to shorten detection and response times. This is especially true for exotic animal diseases that can harm our domestic livestock. These tests could also be used to quickly identify exposed individuals for early treatment or isolation. Another important learning point from both SARS and avian influenza is that agricultural workers may often be the first to acquire these new or re-emerging diseases. Therefore, it is imperative to have adequate healthcare for workers. With healthcare, timely information needs to be collected by public-health personnel to also assess the population health of agricultural workers.

Our public-health and veterinary infrastructure needs to be improved. We must build the expertise, resources, and tools necessary for developing the capacity to respond to threats posed by vector-borne and zoonotic diseases (Smolinski et al., 2003). Our universities need to train more medical entomologists, vector ecologists, mammologists and ornithologists who have a thorough understanding of the interactions among human, animal, and ecosystem health. There is a need to develop interdisciplinary infectious- 
disease centers for training, research, diagnostic systems and data sharing. Furthermore, public-health authorities should look beyond traditional disciplines and training when hiring new epidemiologists and microbiologists. These and other recommendations have been clearly outlined (Smolinski et al., 2003; NRC, 2005).

In the 19th century, Rudolf Virchow stated that animal and human health are inextricably intertwined. Our common environment is where this weaving of lives takes place, hence, we must guard the health of our ecosystems. Recent examples include decreasing wetlands and the subsequent congregation of waterfowl in smaller areas, resulting in outbreaks such as avian influenza and Newcastle disease. Deforestation and the greater interaction of wildlife with domestic animals and humans are likely factors for the emergence of novel viruses such as hendra, lyssavirus, and Nipah (Parashar et al., 2000). Conversely, reforestation and suburbanization are likely contributing factors for the emergence of Lyme disease in the northeastern portion of the United States (LoGiudice et al., 2003). Dramatic weather events have also been linked to disease emergence. This was documented with the outbreaks of Rift Valley fever among ruminants and people in East Africa and the Arabian peninsula (CDC 1998, 2000), following periods of above-normal precipitation and subsequent increases in mosquitoes. We can be sure that diseases will continue to emerge, and the complex relationship between animals, plants, and humans will require the interaction and cooperation of a broader range of scientists and medical professionals. The time to train them is now.

\section{REFERENCES}

Belay ED et al. (2004) Chronic wasting disease and potential transmission to humans. Emerging Infectious Diseases 10 977-984.

Bishop R (2004) The economic impacts of chronic wasting disease (CWD) in Wisconsin. Human Dimensions of Wildlife 9 181-192.

Blendon RJ et al. (2004) The public's response to severe acute respiratory syndrome in Toronto and the United States. Clinical Infectious Diseases 38 925-931.

Bridges CB et al. (2002) Risk of influenza A (H5N1) infection among poultry workers, Hong Kong, 1997-1998. Journal of Infectious Diseases 185 1005-1010.

Center for Infectious Disease Research and Policy (CIDRAP) (2005) Laboratory-confirmed human cases of H5N1 avian influenza, January 2004 to present, 2005, http://www. cidrap.umn.edu/cidrap/content/influenza/avianflu/case-count/avflucount.html.

Centers for Disease Control (CDC) (1981) Rabies in raccoons-Virginia. The Morbidity and Mortality Weekly Report 30 353-355.

Centers for Disease Control and Prevention (CDC) (1998) Rift Valley fever-East Africa, 1997-1998. The Morbidity and Mortality Weekly Report 47 261-264.

Centers for Disease Control and Prevention (CDC) (2000). Update: outbreak of Rift Valley fever-Saudi Arabia, August-November 2000. The Morbidity and Mortality Weekly Report 49 982-985.

Centers for Disease Control and Prevention (CDC) (2002a) Provisional surveillance summary of the West Nile virus epidemic-United States, January-November 2002. The Morbidity and Mortality Weekly Report 51 1129-1133. 
Centers for Disease Control and Prevention (CDC) (2002b) Outbreak of tularemia among commercially distributed prairie dogs, 2002. The Morbidity and Mortality Weekly Report 51 688, 699.

Centers for Disease Control and Prevention (CDC) (2003a) Fatal degenerative neurologic illnesses in men who participated in wild game feasts-Wisconsin, 2002. The Morbidity and Mortality Weekly Report 52 125-127.

Centers for Disease Control and Prevention (CDC) (2003b) Update: multistate outbreak of monkeypox-Illinois, Indiana, Kansas, Missouri, Ohio, and Wisconsin, 2003. The Morbidity and Mortality Weekly Report 52 642-646.

Centers for Disease Control and Prevention (CDC) (2003c) Prevalence of IgG antibody to SARS-associated coronavirus in animal traders - Guangdong Province, China, 2003. The Morbidity and Mortality Weekly Report 52 986-987.

Chang HJ et al. (2004) The impact of the SARS epidemic on the utilization of medical services: SARS and the fear of SARS. American Journal of Public Health 94 562-564.

Cleaveland S et al. (2001) Diseases of humans and their domestic mammals: pathogen characteristics, host range and the risk of emergence. Philosophical Transactions of the Royal Society of London. Series B, Biological Sciences 356 991-999.

Department for Environment, Food and Rural Affairs (DEFRA) (2005a) Economic costs of the foot-and-mouth disease outbreak in the UK in 2001. http://www.defra. gov.uk/corporate/inquiries/lessons/fmdeconcostrev.pdf.

Department for Environment, Food and Rural Affairs (DEFRA) (2005b) Origin of the UK foot-and-mouth disease epidemic, 2001. http://www.defra.gov.uk/corporate/inquiries/lessons/fmdorigins.pdf.

Department of Health and Human Services (DHHS) (2003) Control of communicable diseases: Restrictions on African rodents, prairie dogs, and certain other animals. 42 CFR Part 71.

Emanuel EJ (2003) The lessons of SARS. Annals of Internal Medicine 139 589-591.

Fouchier RA et al. (2004) Avian influenza A virus (H7N7) associated with human conjunctivitis and a fatal case of acute respiratory distress syndrome. Proceedings of the National Academy of Sciences of the USA 101 1356-1361.

Gerberding JL (2004) Julie Louise Gerberding-Director of the Centers for Disease Control and Prevention. Interview by Pam Das. The Lancet Infectious Diseases 4 $178-181$.

Guan Y et al. (2003) Isolation and characterization of viruses related to the SARS coronavirus from animals in southern China. Science 302 276-278.

Hayes EB Gubler DJ (2005) West Nile virus: Epidemiology and clinical features of an emerging epidemic in the United States. Annual Review of Medicine 57 181-194.

Heberlein T (2004) "Fire in the Sistine Chapel": How Wisconsin responded to chronic wasting disease. Human Dimensions of Wildlife 9 165-179.

Hunter PR et al. (2003) Foot and mouth disease and cryptosporidiosis: Possible interaction between two emerging infectious diseases. Emerging Infectious Diseases 9 109-112.

Karesh WB et al. (2005) Wildlife trade and global disease emergence. Emerging Infectious Diseases 11 1000-1002. 
Lanciotti RS et al. (1999) Origin of the West Nile virus responsible for an outbreak of encephalitis in the northeastern United States. Science 286 2333-2337.

Lau SK et al. (2005) Severe acute respiratory syndrome coronavirus-like virus in Chinese horseshoe bats. Proceedings of the National Academy of Sciences of the USA 102 14040-14045.

LoGiudice K et al. (2003) The ecology of infectious disease: effects of host diversity and community composition on Lyme disease risk. Proceedings of the National Academy of Science of the USA 100 567-571.

Manning L et al. (2005) Deliberate contamination of the food supply chain. British Food Journal 107 225-245.

Maunder R (2004) The experience of the 2003 SARS outbreak as a traumatic stress among frontline healthcare workers in Toronto: Lessons learned. Philosophical Transactions of the Royal Society of London. Series B, Biological Science 359 1117-1125.

Miller R et al. (2003) Evaluation of the influence of supplemental feeding of white-tailed deer (Odocoileus virginianus) on the prevalence of bovine tuberculosis in the Michigan wild deer population. Journal of Wildlife Diseases 39 84-95.

National Research Council (NRC) 2005. Animal Health at the Crossroads: Preventing, Detecting, and Diagnosing Animal Diseases. Washington, DC: The National Academies Press.

Osterholm MT (2005) Preparing for the next pandemic. New England Journal of Medicine 352 1839-1842.

Parashar UD et al. (2000) Case-control study of risk factors for human infection with a new zoonotic paramyxovirus, Nipah virus, during a 1998-1999 outbreak of severe encephalitis in Malaysia. Journal of Infectious Diseases 181 1755-1759.

Peck D et al. (2002) Psychological impact of foot-and-mouth disease on farmers. Journal of Mental Health 11 523-531.

Roelke-Parker ME et al. (1996) A canine distemper virus epidemic in Serengeti lions (Panthera leo). Nature 379 441-445.

Russell JB et al. (2000) Potential effect of cattle diets on the transmission of pathogenic Escherichia coli to humans. Microbes and Infection $245-53$.

Sellers RF et al. (1971) Transfer of foot-and-mouth disease virus in the nose of man from infected to non-infected animals. The Veterinary Record 89 447-449.

Siegel JM et al. (1999) AIDS diagnosis and depression in the Multicenter AIDS Cohort Study: The ameliorating impact of pet ownership. AIDS Care 11 157- 170.

Sohn HJ et al. (2002) A case of chronic wasting disease in an elk imported to Korea from Canada. The Journal of Veterinary Medical Science 64 855-858.

Smolinski MS et al. (Eds.) (2003) Microbial Threats to Health: Emergence, Detection, and Response. Washington, DC: The National Academies Press.

Strachan NJ et al. (2003) Foot and mouth epidemic reduces cases of human cryptosporidiosis in Scotland. Journal of Infectious Diseases 188 783-786.

Swaminathan B (2001) Listeria monocytogenes. In: Food Microbiology, Fundamentals and Frontiers 2nd Edition (Doyle MP et al. Eds.) 383-409. Washington, DC: ASM Press. 
Taylor LH et al. (2001) Risk factors for human disease emergence. 356 983-989.

Ungchusak K et al. (2005) Probable person-to-person transmission of avian influenza A (H5N1). New England Journal of Medicine 352 333-340.

Williams ES Miller MW (2003) Transmissible spongiform encephalopathies in nondomestic animals: origin, transmission and risk factors. Revue Science et Technique 22 145-156.

World Health Organization (WHO) (2005) WHO Consultation on public health and animal transmissible spongiform encephalopathies: Epidemiology, risk and research requirements, 1999. http://www.who.int/csr/resources/publications/bse/WHO_CDS_ CSR_APH_2000_2/en/.

Wunschmann A et al. (2004) Pathologic findings in red-tailed hawks (Buteo jamaicensis) and Cooper's hawks (Accipiter cooper) naturally infected with West Nile virus. Avian Diseases 48 570-580.

Zhong NS et al. (2003) Epidemiology and cause of severe acute respiratory syndrome (SARS) in Guangdong, People's Republic of China, in February, 2003. The Lancet $3621353-1358$.

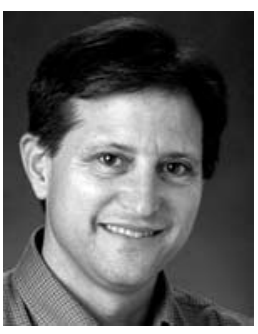

Jeff Bender is an associate professor in the University of Minnesota's College of Veterinary Medicine and has an adjunct-professor appointment in the School of Public Health. From 1995 through 2000, he served in the Acute Disease Epidemiology Section of the Minnesota Department of Health, as an infectious-disease epidemiologist.

Dr. Bender's primary teaching and research interests include emerging zoonotic diseases, disease surveillance, food safety and antimicrobial resistance. He has served as the chair for the National Association of State Public Health Veterinarians Compendium, examining measures to prevent diseases associated with animals in public settings, and as the division head of Veterinary Public Health at the College of Veterinary Medicine. Currently, he is principle investigator on a CDC-funded Cooperative Agreement on Zoonotic Influenza Infections and is director of the Center for Animal Health and Food Safety at the University of Minnesota. 